\title{
A Fuzzy Logic based Agricultural Decision Support System for Assessment of Crop Yield Potential using Shallow Ground Water Table
}

\author{
Mohammad Rafiuzzaman \\ M.Sc. Graduate \\ Faculty of Computer and \\ Information Engineering \\ Sakarya University, \\ Esentepe Campus, Turkey
}

\author{
Ibrahim Çil \\ Professor \\ Department of \\ Industrial Engineering \\ Sakarya University, \\ Esentepe Campus, Turkey
}

\begin{abstract}
Agricultural research is aimed towards increasing the productivity and food quality at reduced expenditure and with increased profit. One of the main challenges of this approach is to equip farmers with adequate and affordable information and control technology; as for higher crop yields, they need advanced expert knowledge to take proper decisions during land preparation, sowing, fertilizer management, irrigation management, integrated pest management, storage etc. In an effort to provide a methodology for better assessment on the functional outcome of this research area, an online fuzzy logic based agricultural decision support system is developed and presented in this paper. The aim of this system is to assist farmers in taking proper decisions for having a better crop production with less cost, despite the adverse nature of the soil on their farming area. Our proposed system focuses on utilizing abundant surface ground water available at the end of the wet season while benefiting from timely access to shallow groundwater from the process of capillary rises so that the farmers can have a better crop yield with or even without the expensive irrigations. The experiment was carried out in the northern and southern (coastal areas) regions of Bangladesh. Fuzzy logic is used in this case to handle uncertain or ambiguous data and knowledge of the input data. Experimental results presented in this paper also show that despite diverse climate nature, farmers can produce a hefty amount dry season crops in the coastal areas by utilizing shallow ground water, which was thought as impossible before. Though the experiment is carried out in Bangladesh only, if successfully implemented, this finding is believed to bring a groundbreaking agricultural advancements for the coastal area farmers in all over the world. Especially in the coastal areas of India, Myanmar, Nepal, Indonesia and Vietnam as their nature of the soil is almost same as Bangladesh.
\end{abstract}

\section{General Terms}

This research exploits and focuses on the following areas:

- Exploring new suitable areas for farming and crop productions.

- Showing the benefits of shallow ground water, which has often been overlooked in providing soil water benefits in traditional irrigated farming systems.

- Developing a Decision Support System which helps farmers to take agricultural decisions to have a better crop production with minimized irrigational costs, without consulting experts.

\section{Keywords}

Agriculture, online Decision Support System, fuzzy Logic, flexible querying, shallow groundwater, Bangladesh

\section{INTRODUCTION}

In Bangladesh agriculture is the single largest production sector of the economy since it comprises about $18.6 \%$ of the country's GDP and employs around $45 \%$ of the total labor force [1]. For sustaining the growing human population (almost 164 million [2]) with such small amount of area $(147,570 \mathrm{~km} 2$ [3]), the only way to increase crop productivity with varied farming situations of this country is thorough planning with an active participation of the farmers.

The agricultural economy of Bangladesh is underpinned by traditional plantings of Wet-Season Rice (T.Aman) and Rabi (dry-season) crops of Irrigated Rice (Boro), Cereals, Vegetables and Fodder Crops. In the case of wheat, consumption is estimated at 2.95 million tons in 2009/10 [4], while production remains closer to 1.0 million tons, which exceeds production levels by three times. Officials say that Bangladesh needs to import more than 2 million tons annual demand of wheat [5] as shown in figure 1. For this reason, we had used Shatabdi, which is one of the fast growing variety of wheat for conducting our experiment.

Traditionally, wheat has been grown in the cooler northern regions of Bangladesh relying on supplementary irrigations from deep tube wells (Figure 2.a), but at the cost of declining water table levels [6]. This crop has not been previously sown in the far southern regions of this country as it was widely accepted as being too risky due to:

- Lack of irrigation resources,

- Higher temperatures,

- Delayed planting times and

- Increased salinity levels in southern regions.

But our experimental results show that high yields $\left(>2.5 \mathrm{tH}^{-1}\right)$ are achievable in some southern regions of Bangladesh, even without any irrigation because of the presence of shallow ground water tables [7] (Figure 2.b).

An assessment of irrigation potentiality of ground water using water quality index tool has been explained in [8]. But it is very limited. The scarcity of groundwater and its importance is discussed on [9]. Against it, in this research work, shallow ground water has been considered as an underutilized renewable resource for in-situ water used by Rabi crops, such as Wheat or Mungbean in southern regions of Bangladesh. This research has shifted local views with the introduction of new technology, improved agronomy, and farmer training. It has demonstrated the potentiality of achieving grain yields between 3.0 to 4.0 t ha- 1 using even one supplementary irrigation in southern Bangladesh. 


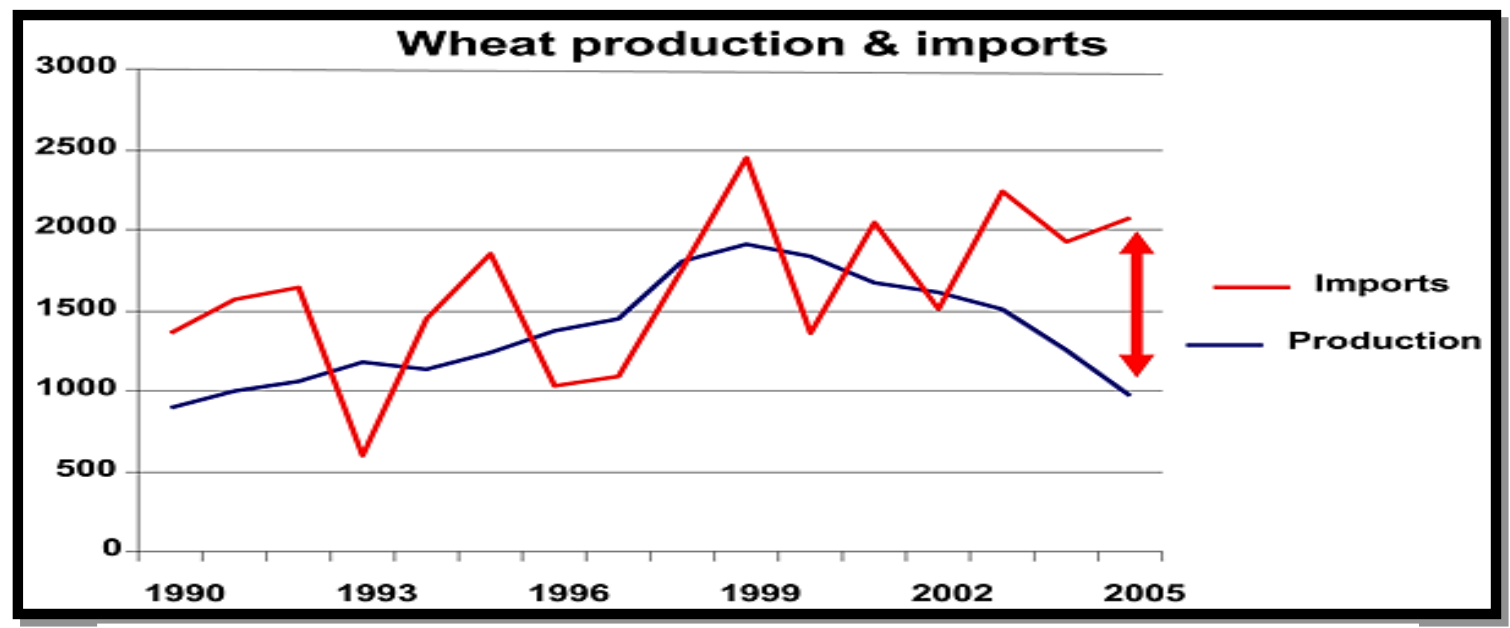

Fig 1: Wheat production and import of Bangladesh

The idea of creating computerized Decision Support System for Farm Management is not new [10]. In spite of that, in this paper, we presented a system which is designed in such a way from where the farmers will get the information of how much yield of crops they can expect if they apply a certain amount of water for irrigation with the presence of a certain amount of water level to the ground. As our experimental results confirm, crops such as wheat do exploit the natural cycle of shallow ground water through the process of capillary rise with grain yields of $2.38 \mathrm{tH}-1$ (dry-land i.e. no irrigation) and $3.65 \mathrm{tH}-1$ (one irrigation). In this way, the farmers will get an idea of how much crop production they might expect in the presence of shallow ground water tables in their farming area. By this, they will be able to decide how much money they should spend on expensive irrigations, as they can expect a good amount of yield without even the need of an irrigation.

The rest of the paper is organized as this, we first review some related works in fuzzy logic based DSS technology in section 2. In section 3 we have explained the experimental model of our system. Section 4 discusses our experimental procedures where section 5 discusses the experimental results of our system. We then conclude the paper in section 6 with some discussions about the system results and its effects on the local farmers.

\section{RELATED WORK}

In the field of DSS, a few endeavors are seen which utilizes the fuzzy logic that can compose and handle all data related to

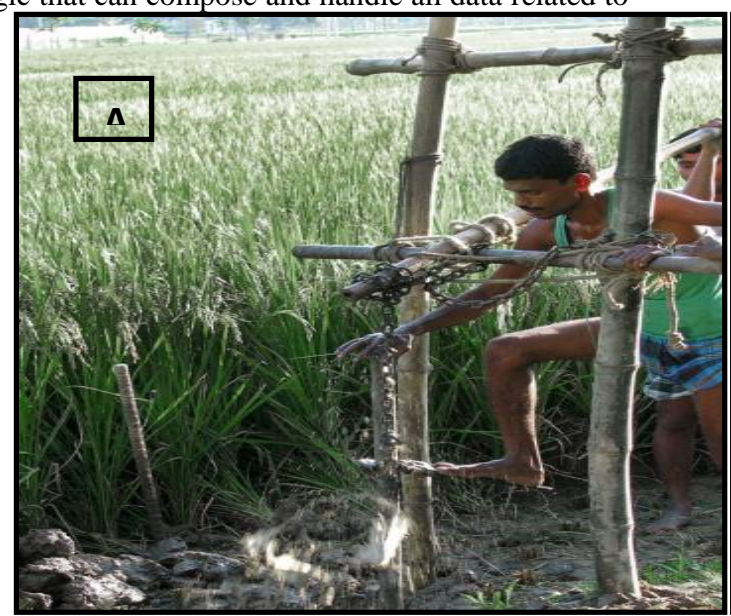

making effective decisions [11]. The essential strategy used is inference based rules. The advantages reported from the expanding utilization of fuzzy incorporate more exact decisions, adaptability, enhanced quality and minimization of human irregularities [12].

How fuzzy logic imitates the logic of human thought is explained in [13], which is much less rigid than the calculations computer generally perform. A neat description regarding the origin of DSS, theory development and DSS application development is presented on [14]. In [15] a report is presented on the use of Decision Support System in agriculture as a state of the art and the disadvantages of DSS in being adopted by farmers.

Irrigation water quality for sugarcane crops has been discussed on [16]. [17] Presents an automated water irrigation system in Nepal. The various types of DSS and the usage of linguistic variables and values in Decision Support System have been discussed in [18]. While [19] discusses some problems of irrigation due to Tsunami in the Tsunami affected coastal areas of India, [20] discusses some agricultural problems and their solutions in America. Caroline Parker [21] describes how to increase the feasibility of DSS by making it user-centered. Some decision support systems play out the undertakings of examination of production efficiency, resource reserves and shortage [22].

Fig 2: (a) Shows the deep tube wells in northern region (Dinajpur), (b) Shows the shallow ground water in southern region (Khanjapur site in Barisal) at season end, showing the water level in a fish pond indicating a high water table for the site. 


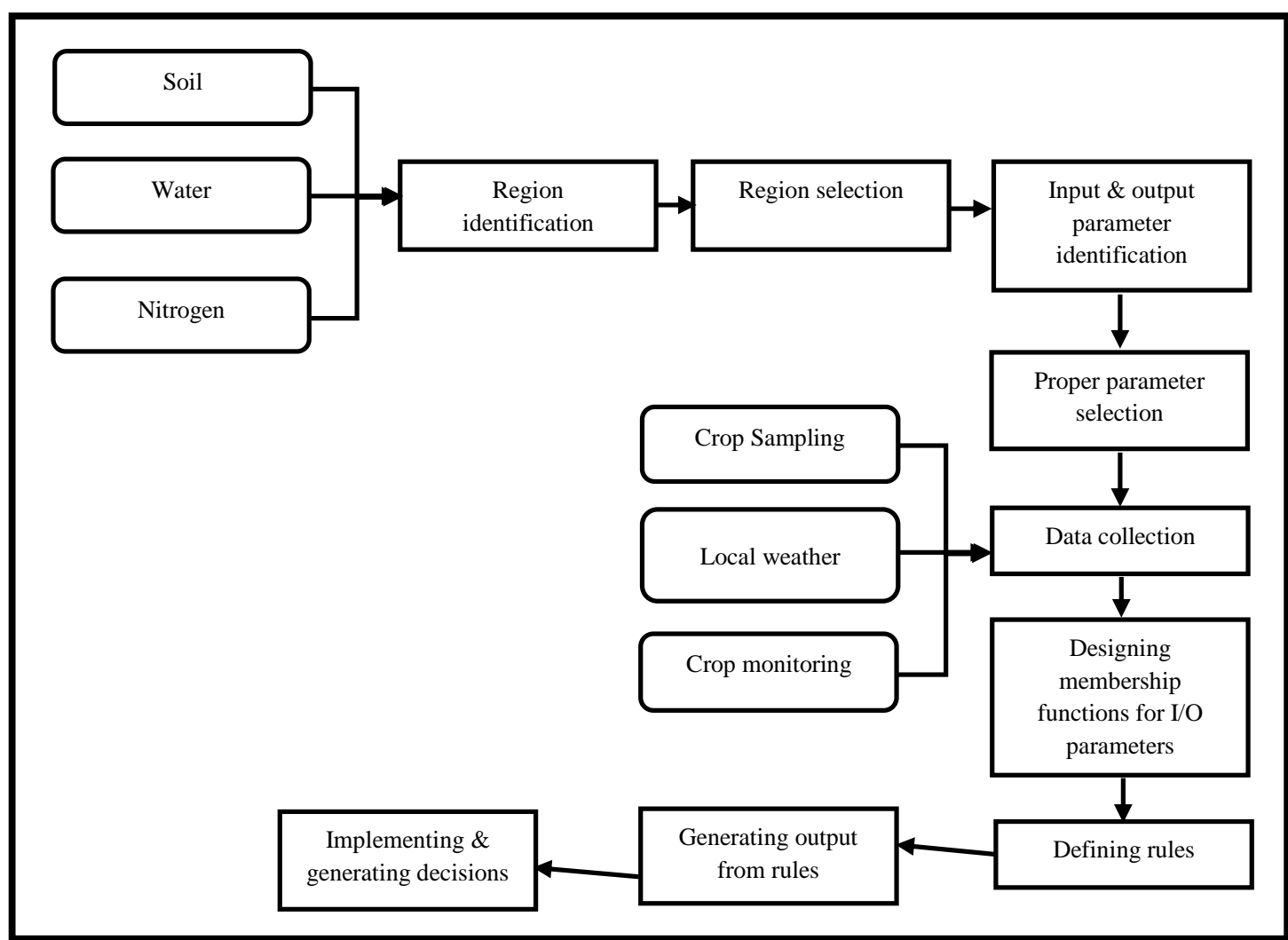

Fig 3: General work flow diagram of our online fuzzy logic based farmer assisting system.

Literature reviews above generally show focus on usercentered design. This can be accomplished by taking interviews and survey of farmers. But in most of the cases we witnessed the following reasons of lack of uptake of DSS in these cases:

- The complexity of the software's interaction with the user.

- Accessibility and required accuracy of inputs.

- Need to answer the right questions.

- The cost benefit of using the system.

- Adjustments to the user working patterns and existing organizational structures.

On the contrary, our proposed DSS has the support of internet for real-time processing and provides farmers with suggestions in their own language, which is necessary to increase the efficiency of production of crops, conforming to environmental constraints. Moreover, the integration of fuzzy logic and knowledge management into the system expands its possibilities and improves the quality of solutions.

\section{EXPERIMENTAL SETUP}

Total two types of experiments have been carried out for our research work. One is the field experiment to determine the nature of the soil and the other is the computerized experiment for building the end user interface in a best suitable way for helping the end users i.e. farmers to take proper decisions.

\subsection{Field Experimental Setup}

The basic experimental setups used to carry out the field experiment are as follow:

- For our experiment, on-farm trials which were conducted in:

○ Northern farms (Dinajpur, $25^{\circ} 38^{\prime} \mathrm{N} 88^{\circ} 39^{\prime} \mathrm{E}$ ) and o Southern farms (Bhola, 22.583N, 90.635E, Patuakhali, 22.432N, 90.322E) of Bangladesh.

- The amount of soil water and nitrogen on the ground were considered for site characterization and region selection.

- Simulations use the same soil type for both locations (i.e. Patuakhali and Dinajpur).

- $\quad$ Climate files for Patuakhali and Dinajpur 1981-2007 (27 years).

- Water table set on 1 st December each year at:

- $\quad 350 \mathrm{~cm}, 1010 \mathrm{~cm}, 2050 \mathrm{~cm}$ - Patuakhali

o $1020 \mathrm{~cm}, 1160 \mathrm{~cm}, 1480 \mathrm{~cm}, 2520 \mathrm{~cm}, 2390 \mathrm{~cm}$, $2750 \mathrm{~cm}$ - Dinajpur

- Crop Variety: Shatabdi

- Fertilizer: $100 \mathrm{~kg} / \mathrm{ha}$ at sowing

- One irrigation at 20 days after sowing

- $\quad$ Second irrigation at 40 days after sowing

\subsection{Computerized Experimental Setup}

This experimental setup is used to build the user interface, fuzzy inference system, and others as discussed below:

\subsubsection{General framework}

Figure 3 shows the general framework of our system. As we can see from this figure, we have identified regions for our experiment according to the soil type, the presence of water and nitrogen to the ground of that area. After that, we have separated the regions according to those parameters and identified them as Northern and Southern regions, as all of those parameters differ from each other drastically for each of those regions. After selecting the regions we are going to set the input and output parameters for them according to our system criteria. After selecting appropriate input and output parameters for the regions we are going to use data collected 


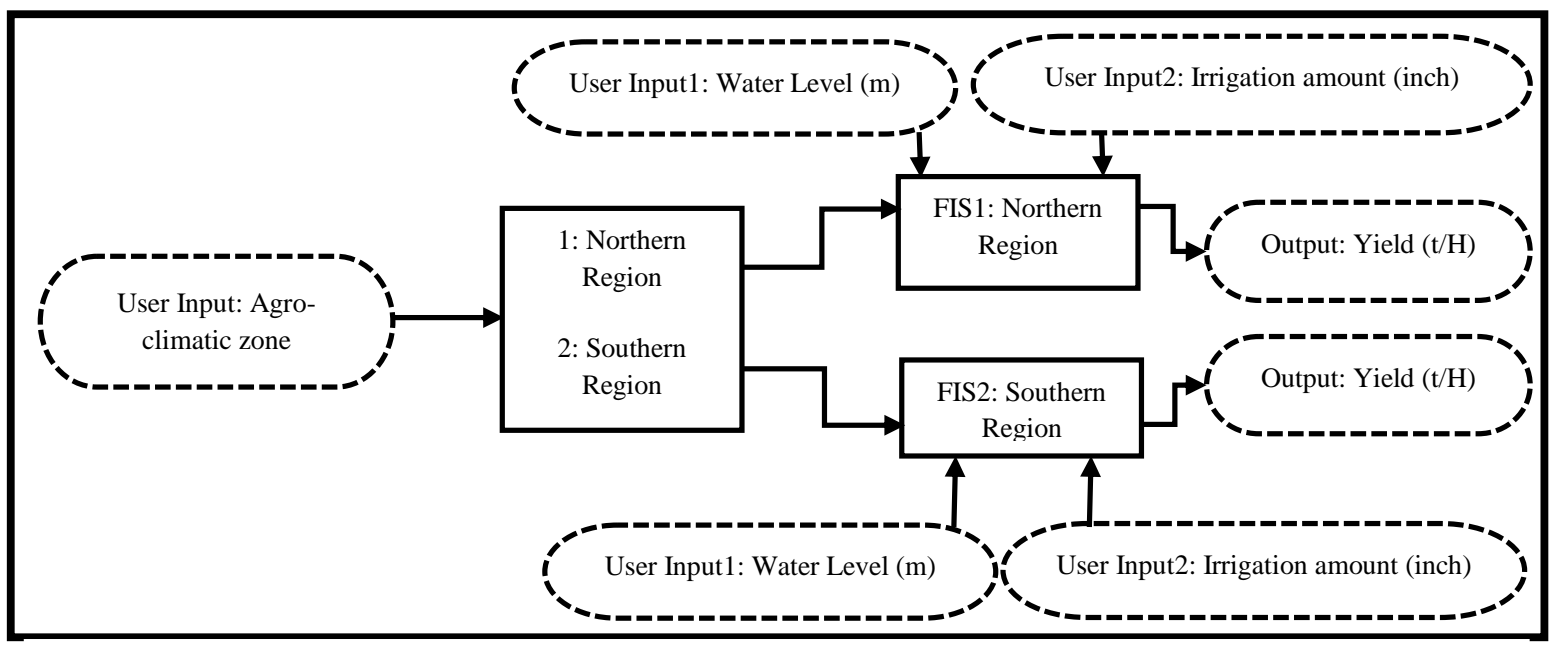

Fig 4: Block diagram of our proposed online fuzzy logic based agriculture decision support system

from the crop sampling, local weather and crop monitoring from each of the regions for designing membership functions for both of the input and output parameters. After designing the membership functions we are going to define fuzzy rules and generate the output according to those rules from the fuzzy inference system. From there the farmers will be able to take appropriate decisions regarding the amount of irrigation needed for a certain amount of crop yield.

\subsubsection{Language selection}

Though there is a lot of increase of modern technology in the rural areas of Bangladesh and internet is available in almost all parts of this country, yet there are problems for the farmers in getting information from the internet as all of the information are in English and the farmers of this country are not that much convenient in English except their own mother language Bangla. Since the initial motivation of this research work was to help the farmers of Bangladesh, both English and Bangla languages are used for the main user interface of our web system, so that the intended main end users i.e. farmers of this country can easily understand it. English is kept for the use of the international users. But we will be always open to updating our system and take new languages as per need.

\subsubsection{Handling imprecise input data}

The final outcome of our system is made with the imprecise input parameters which are very much useful in making decisions in real time environment where the input is always a range of vague values. For handling this uncertainty, Fuzzy Logic is used in our system for interactive decision making.

\subsubsection{Designing system module}

Our system consists of two modules, one is developed for end user interface (for farmers) as a website using .NET, SQL Server 2012, MVC 4 and other web developing tools. It gives general information about the region, water level description and the amount of irrigations needed for the specific crops. The second module is developed in MATLAB's fuzzy logic toolbox which gives the information about the probable yield of the crop according to the input parameters. All the inputs and output parameters from this module are given to our SQL server. From there the data is collected by our MVC module and displayed on the website; so that the farmers can take appropriate decisions for getting a good amount of yield with a certain amount of irrigation and water level present to the ground. Figure 4 shows this system block diagram of our proposed system

\section{EXPERIMENTAL PROCEDURE}

Decision-making is a process which decision makers use to arrive at a decision. There are several websites available which provide agriculture information for decision making. But very few of them provide exact information necessary for the users of a specific region with specific purposes, especially in Bangladesh.

Although due to increasing awareness and use of computers in almost all the fields, nowadays internet has also reached in rural areas of Bangladesh. But still, there is a problem of understanding, as generally websites provide information in English which is not understandable by most of the farmers. Our attempt has also solved this language barrier as our proposed online decision support system's main interface is designed in both Bangla, the national language of Bangladesh and English. Providing agriculture information to the farmers for having better crop yield with minimum water resource is the main issue of this system. For this purpose we have designed our system with the following steps:

- Collecting data,

- Analyzing data

- Designing fuzzy inference system (FIS)

- Designing end user interface

\subsection{Collecting the Data}

Data used for our experiment were collected from on-farm trials which were conducted in 2007-2010 to demonstrate new wheat varieties and appropriate management in southern farms of Bangladesh. These farms were divided into five regional areas, two of which are reported in this paper (Bhola22.583N, 90.635E, and Patuakhali-22.432N, 90.322E). For site characterization and input parameter selection the following normal experimental practices were carried out:

- Site characterization based on

- Soil

- Water and

- Nitrogen

- Local weather

- Crop monitoring and

- $\quad$ Sampling 


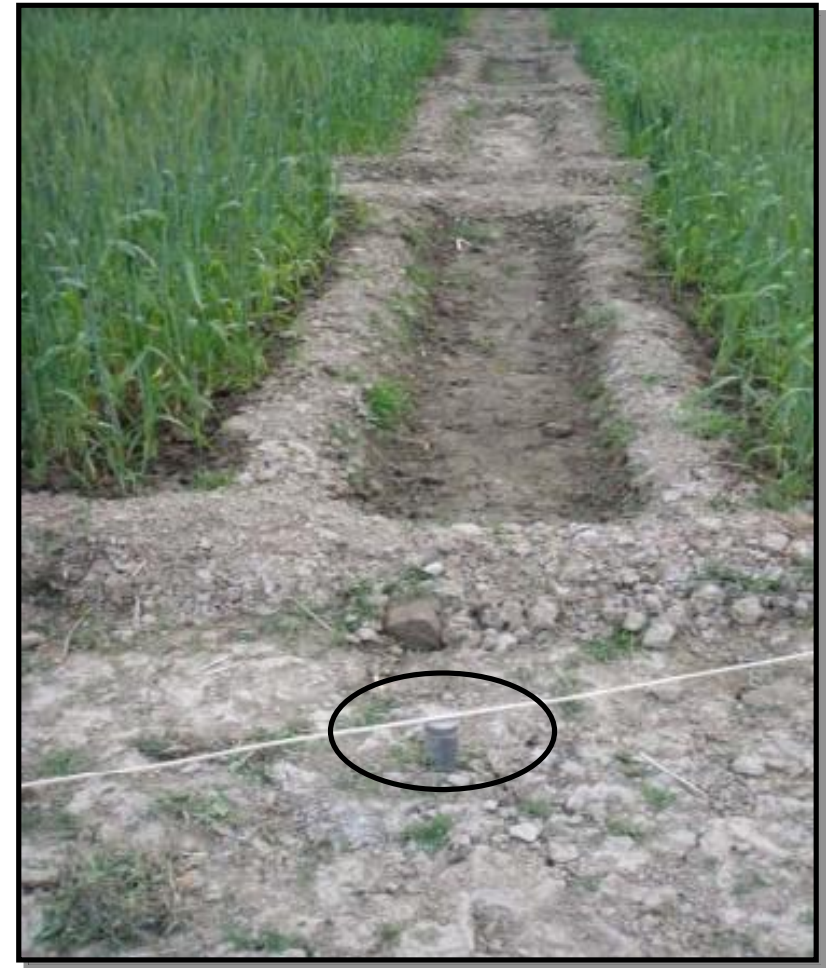

Fig 5: Installation of piezometers (2008/09) at 30 locations to monitor changes in groundwater during the season.

These experimental practices were carried out during the December to March growing season. Ground-water data were obtained from the Bangladesh Water Development Board (BWDB) [23] and analyzed for spatial trends in the depth of shallow ground water for the case study regions.

Piezometers as shown in figure 5, were installed to a depth of $2.5 \mathrm{~m}$ at experimental sites (2008) and monitored at fortnightly intervals during the season. Replicated crop quadrat samples were collected at maturity for grain yield and biomass. Water balance modeling of the system was carried out using APSIM-SWIM [24] to estimate the contribution of capillary rise to crop water use.

\subsection{Analyzing the Data}

Analysis of "Bangladesh Water development Board (BWDB)" records indicate significant differences in annual fluctuations in depth to ground water for northern regions (Figure 6.a) in the order of 3 to $6 \mathrm{~m}$ while more shallow tables predominate in the southern regions (Figure 6.b). Piezometer data are shown in Figure 7, from the trial sites in 2008-09 at Bhola and Patuakhali indicate free water within $1.0 \mathrm{~m}$ of the root front during crop growth; whereas wheat roots were commonly found 1.2 to $1.8 \mathrm{~m}$ below the surface. This is confirmed by soil sampling of pre and post wheat crops, finding soil water at or near drained upper limit at a depth of $0.9-1.5 \mathrm{~m}$.

\subsection{Designing the Fuzzy Inference System (FIS)}

For handling imprecise input data Fuzzy Inference System (FIS) of MATLAB 2013 was used. This development was carried out according to the following steps:

- The first step to developing agricultural based fuzzy inference system was to discover the vital parameters. We have picked such parameters where the dubiousness is regularly experienced. As the output of our system is the amount of crop yield, the important parameters considered are mainly the present ground water level and the amount of irrigation water needed from where the related output crop yield is generated. Our System is developed around these parameters. Uncertainty is more common in the both input and output parameters.

- The second step is to design membership functions of the selected parameters. The careful design of membership functions will generate the correct output.

- The third step is to compose the rules for the fuzzy inference system.

Two important regions i.e. northern (Dinajpur) and southern (Bhola \& Potuakhali) parts of Bangladesh were selected and for each region separate fuzzy inference systems were developed. Wheat was selected as the testing crop. Figure 8 shows the FIS for northern region and figure 9 shows the FIS for the southern region along with their input and output membership functions.

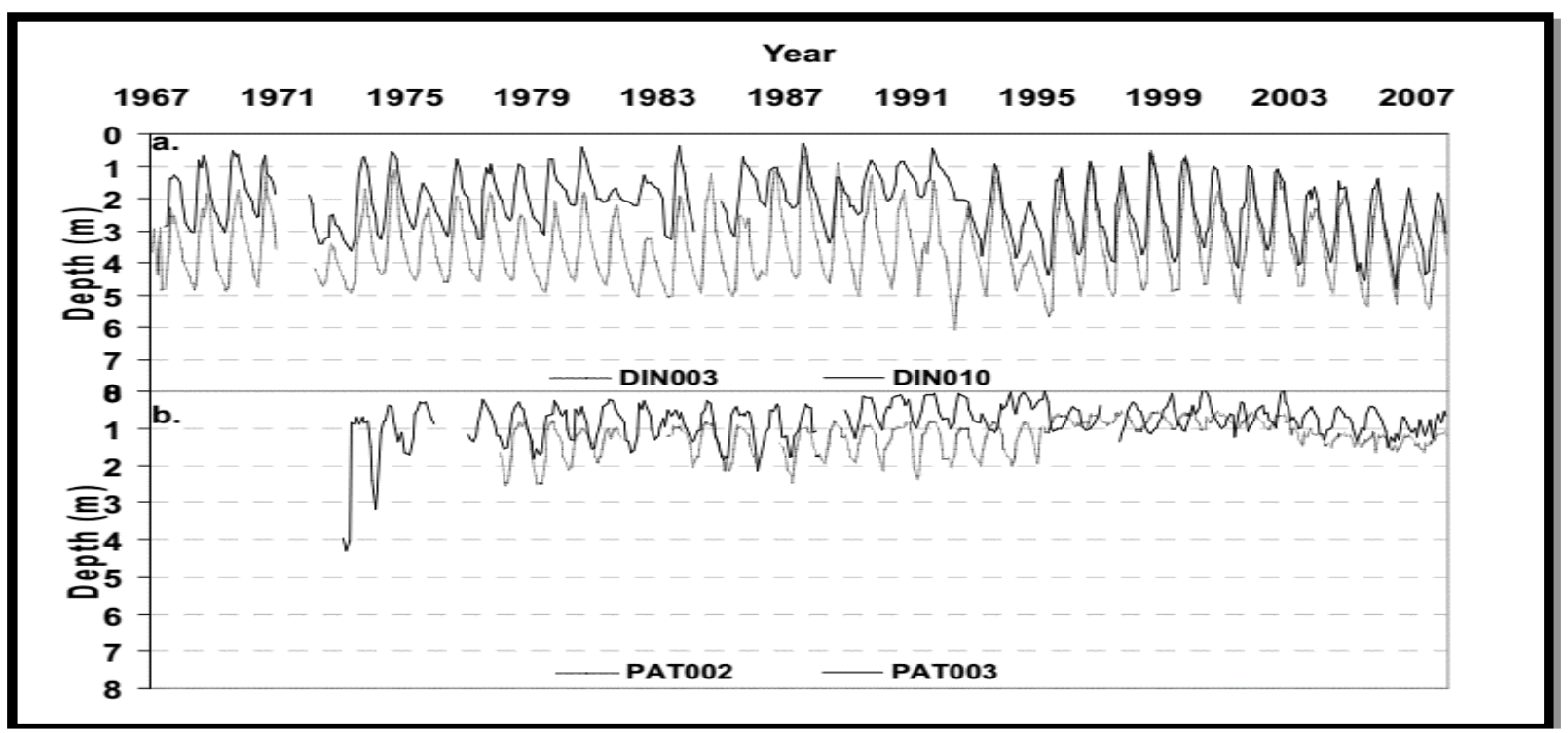

Fig 6: Comparison of monthly mean depth to ground water $(\mathrm{m})$ for northern (a. Dinajpur 25.621N, 88.635E) and southern (b. Patuakhali 22.432N, 90.322E) regions. Data obtained from BWDB. 


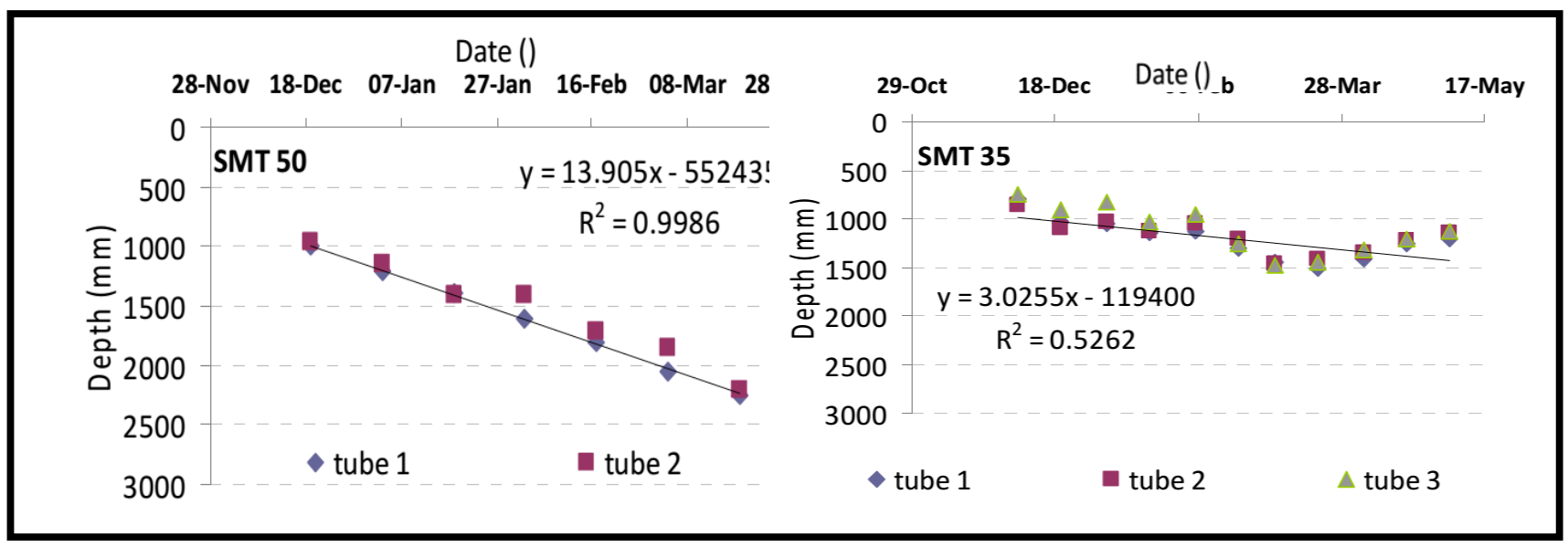

Fig 7: Piezometer data showing change in water tables at Bhola and Patuakhali during the 2008 to 2009 season.

\subsubsection{Defining input membership functions}

Fuzzy membership functions are needed for all input and output variables in order to define linguistic rules that govern the relationship between them. In our system, the designed FIS works as per the input parameters. Once an input is given by the user, appropriate rules will get fired and the output will be given by the system. For both of the regions, the input membership functions include mainly,

- Water depth: The water depth has been defined from the data collected from BWDB records as depicted in figure 6 and has been divided into three membership function, Depth0 (water level is very near to the upper ground), Depth1 (water level is a little bit down from the upper level), Depth2 (water level is a much down from the upper level). The membership functions assigned to it are $Z \& P i$ curves (zmf, pimf) [25] as they are able to produce the best-optimized outputs from their corresponding inputs for our system.

- Irrigation amount: The amount of irrigation has been defined using the Irrigator's Equation [26]:

$$
Q \times t=d \times A
$$

$\mathrm{Q}=$ Flow rate of the water source, in cubic feet per second (cfs),

$\mathrm{t}=$ Set time or total time of irrigation (hours),

$\mathrm{d}=$ Depth of irrigation water (inches),

$\mathrm{A}=$ Area irrigated (acres).

There are about 10,000 deep tube-wells (DTW's), 15,000 shallow tube-wells (STW's) and 40,000 low lift pumps (LLP's) operating in Bangladesh, each with a capacity of 0.5 and 3.0 cubic feet per second (cusec) [27]. So we have set the value of $Q$ between 0.5 to $3.0 \mathrm{cfs}$. The value of ' $\mathrm{t}$ ' has been defined between 5 to 6 hours and the value of ' $\mathrm{A}$ ' is 1 hectare $=2.47$ acres in our system. From the values of ' $\mathrm{d}$ ' obtained from the above equation, we have divided the amount of irrigation into three different membership functions, I0 (no irrigation), I1 (one irrigation) I2 (two irrigation). The membership functions assigned to it are also $\mathrm{Z} \& \mathrm{Pi}$ curves (zmf, pimf) [25].

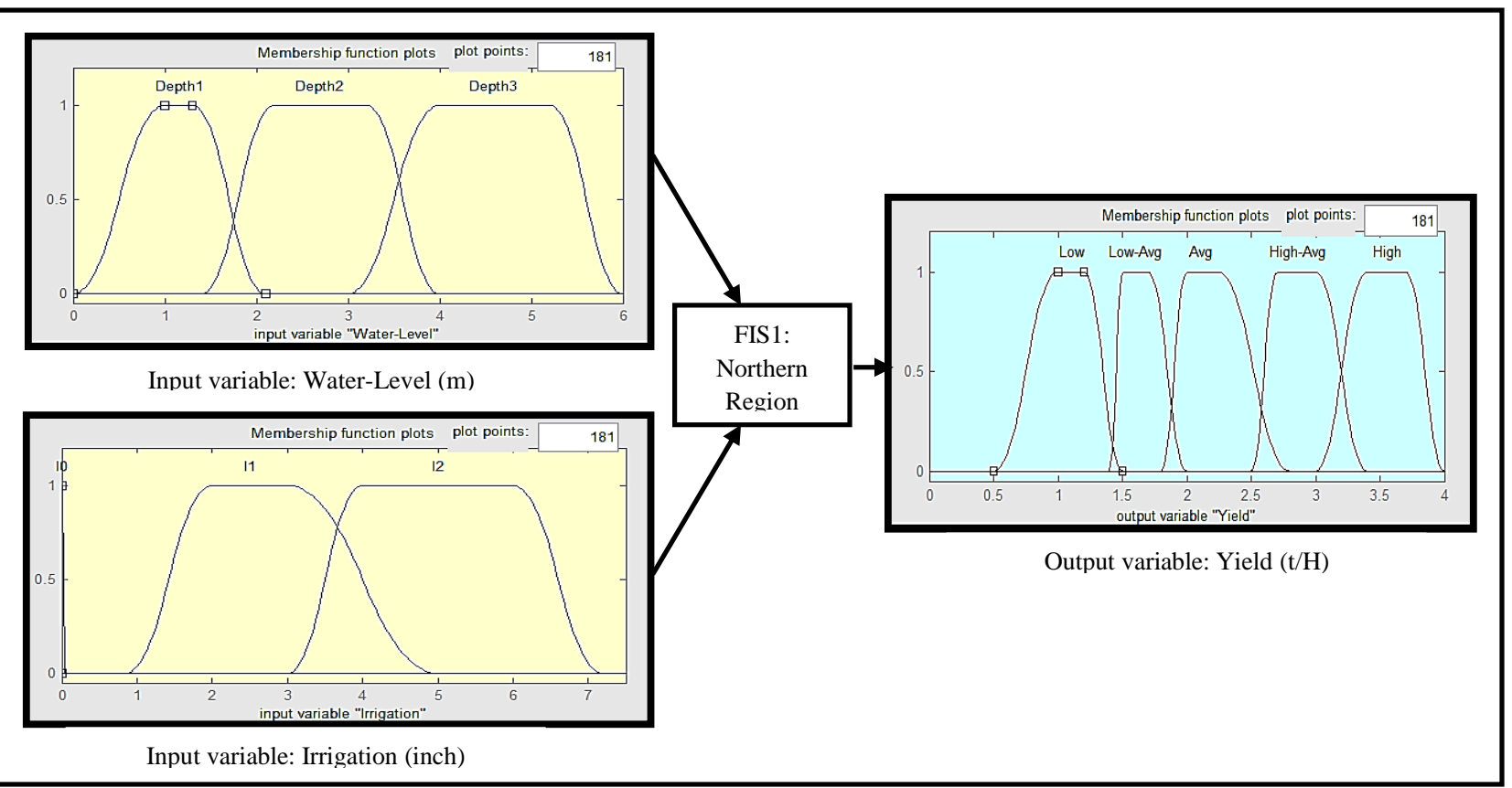

Fig 8: FIS interface for FIS1-Northern Region. 


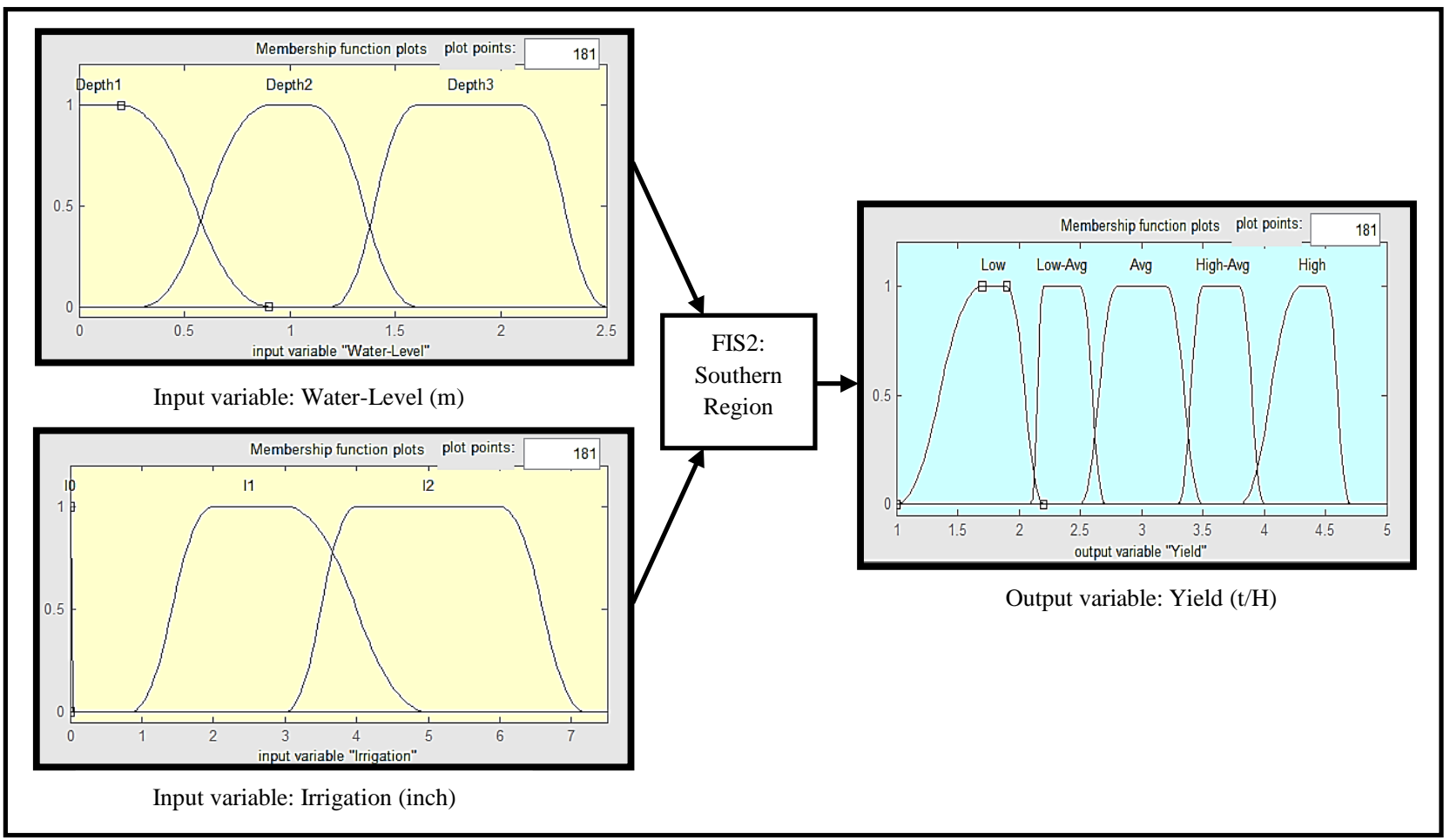

Fig 9: FIS interface for FIS2-Southern Region.

\subsubsection{Defining Fuzzy rules}

A very important task in fuzzy controller design is the development of fuzzy rules for the system. The development of these rules depends in large on the experience and knowledge of the designer about the system. In our system the rules for both FIS1 and FIS2 have been defined as follows:

\section{a. Rules for FIS1-Northern Region}

The FIS for northern region with given input and output membership functions, has been designed with total 9 rules as given bellow:

- If (Water-Level is Depth1) and (Irrigation is I0) then (Yield is Low-Avg)

- If (Water-Level is Depth1) and (Irrigation is I1) then (Yield is Avg)

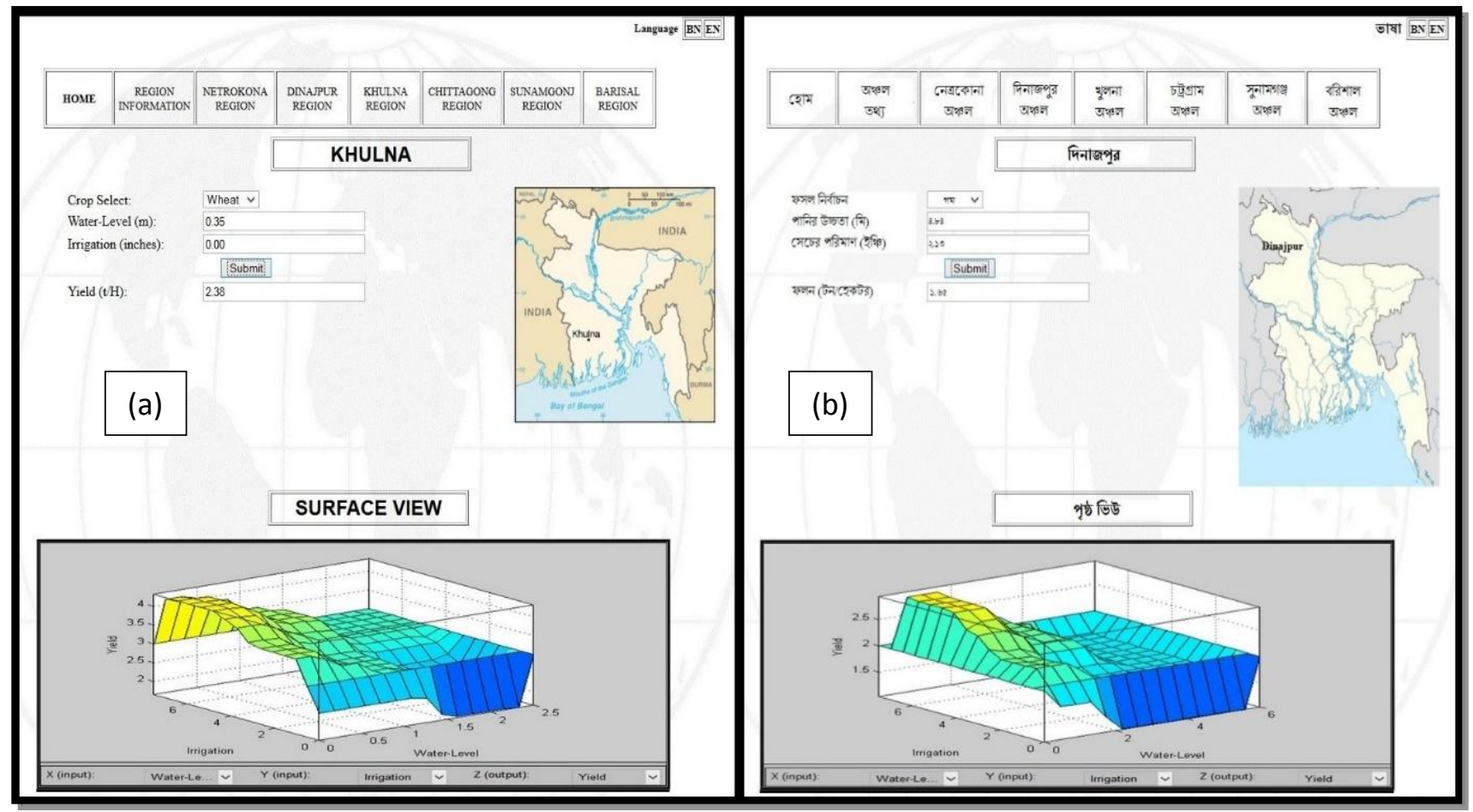

Fig 10: Screenshot of the web user interface of our system in (a) English, (b) Bengali language 


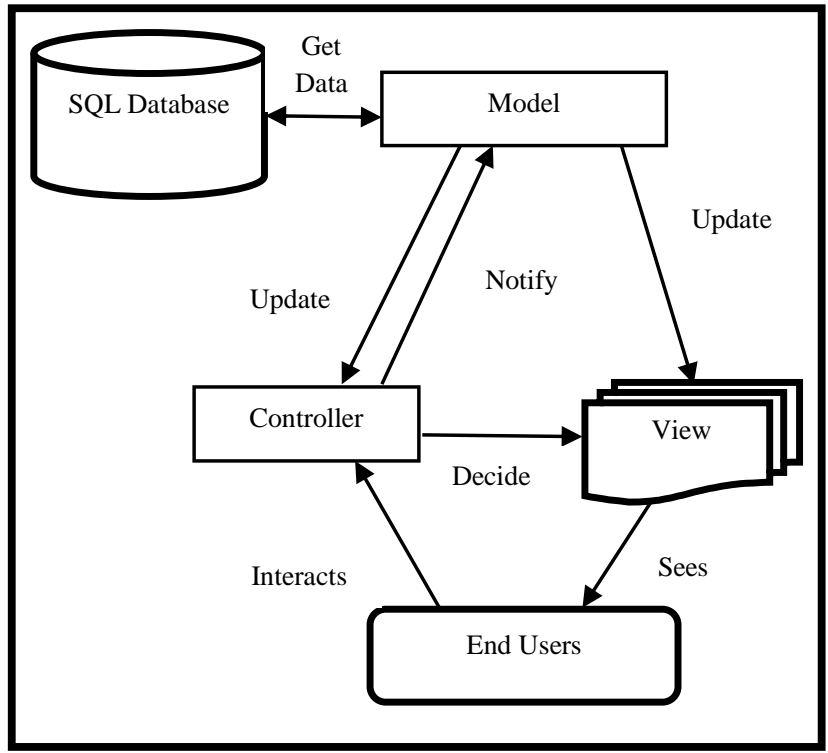

Fig 11: MVC model for the web system.

- If (Water-Level is Depth1) and (Irrigation is I2) then (Yield is High-Avg)

- If (Water-Level is Depth2) and (Irrigation is I0) then (Yield is Low)

- If (Water-Level is Depth2) and (Irrigation is I1) then (Yield is Low-Avg)

- If (Water-Level is Depth2) and (Irrigation is I2) then (Yield is Avg)

- If (Water-Level is Depth3) and (Irrigation is I0) then (Yield is Low)

- If (Water-Level is Depth3) and (Irrigation is I1) then (Yield is Low-Avg)

- If (Water-Level is Depth3) and (Irrigation is I2) then (Yield is Low-Avg)

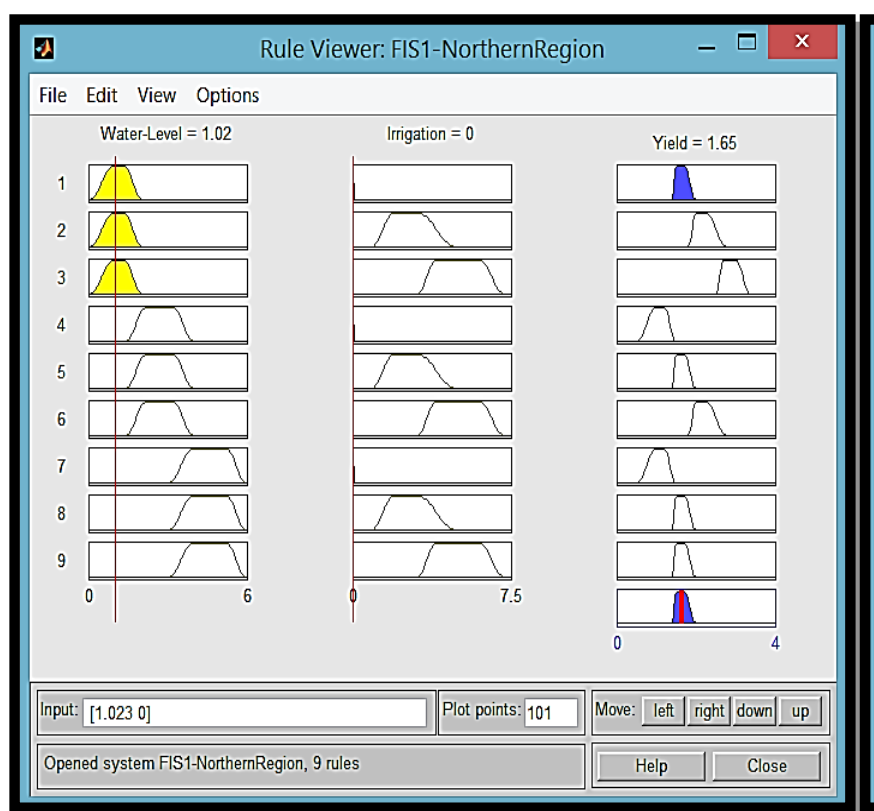

\section{b. Rules for FIS2-Southern Region}

The FIS for southern region with the given input and output membership functions, has been designed with total 9 rules as given bellow:

- If (Water-Level is Depth1) and (Irrigation is I0) then (Yield is Low-Avg)

- If (Water-Level is Depth1) and (Irrigation is I1) then (Yield is High-Avg)

- If (Water-Level is Depth1) and (Irrigation is I2) then (Yield is High)

- If (Water-Level is Depth2) and (Irrigation is I0) then (Yield is Low-Avg)

- If (Water-Level is Depth2) and (Irrigation is I1) then (Yield is Avg)

- If (Water-Level is Depth2) and (Irrigation is I2) then (Yield is High-Avg)

- If (Water-Level is Depth3) and (Irrigation is I0) then (Yield is Low)

- If (Water-Level is Depth3) and (Irrigation is I1) then (Yield is Low-Avg)

- If (Water-Level is Depth3) and (Irrigation is I2) then (Yield is Avg)

\subsubsection{Defining Output membership function}

In our experiment, the output for all the FISs is the amount of wheat crop yield in $\mathrm{tH}-1$ for the specific regions. The membership function assigned to the output is $\mathrm{Pi}$ curves (pimf) [25]. The system will fire the appropriate rule from the particular FIS and finally will give the desired output. The output variable 'yield' has been divided into five membership functions; low, low average, average, high average and high yield (in tH-1).

\subsubsection{Supplying MATLAB file to Visual Studio}

- Step1: In MATLAB we have opened "Deployment Project" tab.

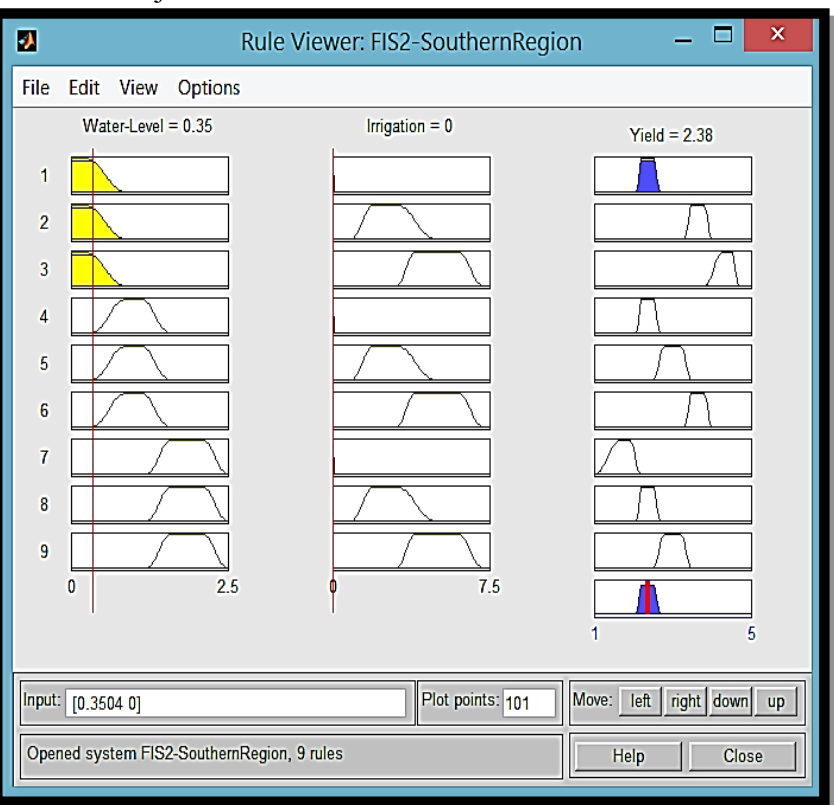

Figure 12: (a) Rule Viewer: FIS1-NorthernRegion, (b) Rule Viewer: FIS2-SouthernRegion 
- Step2: In the "Deployment Project" tab we have saved our MATLAB function file by selecting ".NET Assembly" as the type.

- Step3: In the next window we have pressed the "Add Class" button and gave a class name. After that, we have added our MATLAB file under that class and built it.

- Step4: After building the file, in Visual Studio, under the project menu we have selected the "Add Reference" section from where we have chosen our saved MATLAB native.dll class file.

\subsection{Designing the End User Interface}

The end user interface of our system is a web portal from where the farmers will get an estimated amount of crop yield (in $\mathrm{tH}-1$ ) for a specific region and for a specific crop (wheat in this system). The output is generated according to the irrigation amount of water (in inches) and water level (in meter) present on the ground. According to the estimated crop yield from the output, the farmers will be able to take a decision on how much water they should use as irrigation for a certain amount of water level presented on the ground in order to get a good amount of crop yield. Figure 10.a shows a sample screenshot of the web user interface of our system in English and figure 10.b shows the screenshot in Bangla, the native language of the Bangladeshi people. The web application was designed using MVC 4 and SQL-Server 2012 as backend database which in details is discussed below:

\subsubsection{SQL Server}

All possible imprecise input values of water-level and irrigation level with all of their corresponding output values of crop yields generated from FIS of MATLAB is stored in our database using SQL Server 2012. All of these values were separated according to their corresponding regions by using the region id as a foreign key in their data table. New data types like bigint-8-byte integer type, SQL variant were supported by SQL Server 2012. It allowed the storage of data of different types. There is also a table data type which allows our application to store results temporarily for later use. It included local backing for overseeing XML data, notwithstanding relational data. After generating all the necessary data, the SQL server was connected to our MVC model which is discussed below.

\subsubsection{Data access in MVC from SQL Server}

The controller responds to URL requests, gets data from the model and hands it over to the view. The view then renders the data. In our system entities have been used as the model for data access (Fig 11). We have retrieved data from our SQL server database using entity framework. For this purpose we have used the following steps:

- Step1: We have installed entity framework using nugget package manager.

- Step2: We have added database related context class file to the model folder. This class is inherited from the DbContext class under System.Data.Entity namespace.

- Step3: We have added a connection string to the web.config file in the root directory.

- Step4: We have mapped our database model class to the database table using "Table" attribute.

- Step5: We have made required changes to "Details()" action method in the database related controller.

- Step6: We have pasted the "SetInitializer $<>$ " function of "Database" class in "Application_Start()" function, in Global.asax file. As existing database do not need database initializer, so we have turned it off.

\subsubsection{MVC Pattern}

The MVC patterns in our system was used for:

- Decoupling the GUI from the data.

- Giving the ability to provide multiple views for the same data.

- Separating objects into three important sections [28]:

a. Model

This is where our application data objects are stored. That means our database is connected with it and we used it to retrieve data from our database. It also feeds our controller according to the user interface.

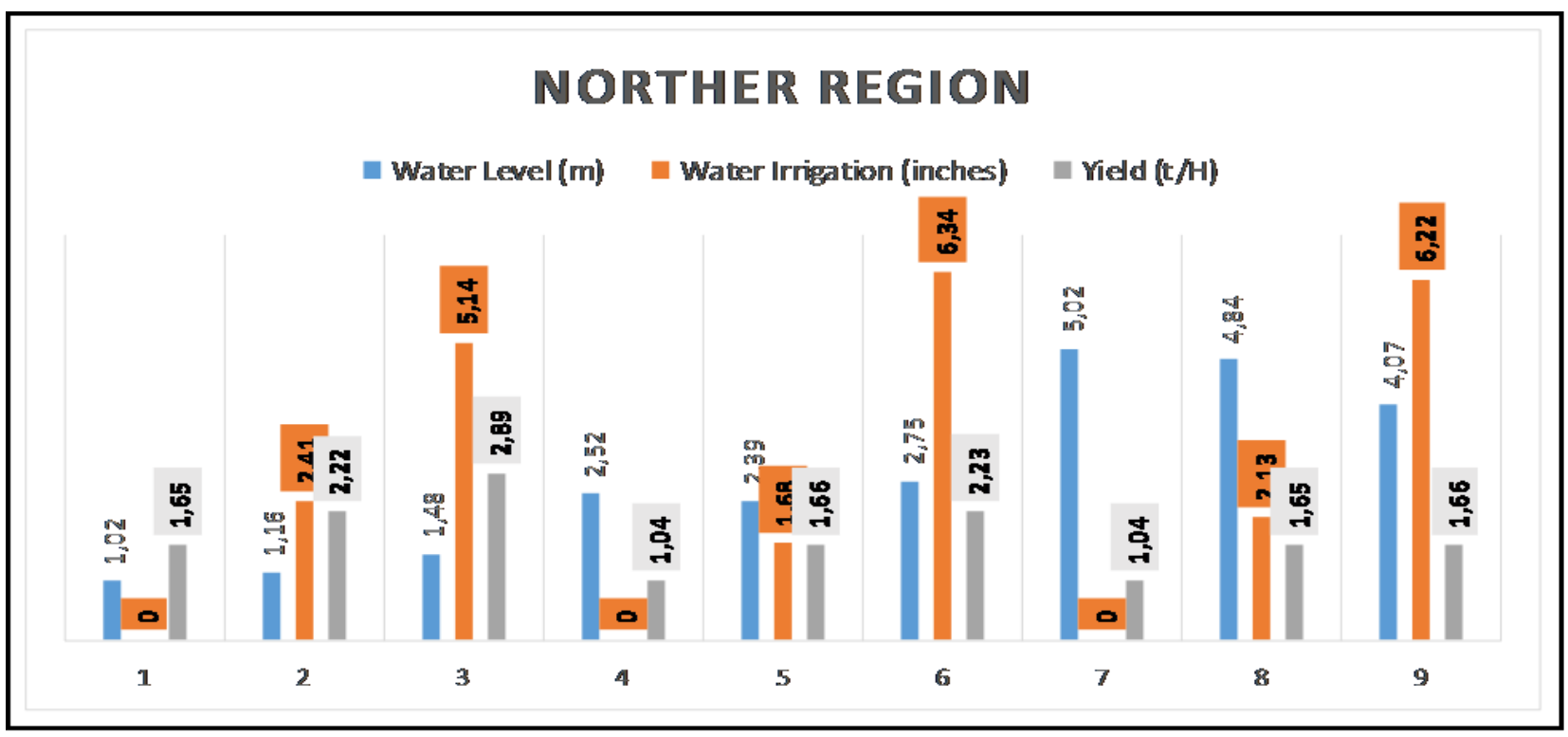

Fig 13: Potential Rate of crop yield in northern Bangladesh with a certain level of irrigation and water level present on the ground. 


\section{b. View}

In our system, a view is what's presented to the users and how users interact with the web site. When a user is supposed to retrieve information related to the yield of a crop, he sees data from here. Then users perform events like search and execute the actual query with selection operations. All these outputs are stored in data grid which is presented in the view as the total possible yield of crops.

Our view is made with HTML. It gets information from the controller. The controller fetches that information from the model and passes it to the view. The view then uses them to generate an output to the end user.

\section{c. Controller}

In our system, the controller updates the view when the model changes. It also adds event listeners to the view and updates the model when the user manipulates the view. The controller modifies the model according to the user interaction. We have used persistent data in this case by making an async save of the data to the server. Persistent data is used so that the same model can be reused with multiple data stores just by constructing controllers with different data stores.

\subsubsection{Performance enhancement}

For better error resiliency, data pages are checksummed, and optimistic concurrency support has been added to enhance the performance. Permissions and access control have been made more granular and the query processor handles simultaneous execution of queries in a more effective manner. Partitions on tables and indexes are bolstered locally, so scaling out a database onto a cluster is easier. SQL CLR (Common Language Runtime) was acquainted with SQL Server to let it coordinate with the .NET Framework [29].

\section{EXPERIMENTAL RESULTS}

Figure 12 shows snapshots taken during generating the output from the fuzzy rule viewer from both of the FIS1 and FIS2.
From figure 12(a) we can see that given input i.e. Water-Level at Depth1 (1.02 $\mathrm{m}$ from the ground) \& irrigation amount at I0 (no irrigation) generate output crop yield of $1.65 \mathrm{tH}-1$ for northern regions. While Figure 12(b) shows that, given input i.e. Water-Level at Depth1 $(0.35 \mathrm{~m}$ from the ground), irrigation amount at I0 (no irrigation) generate output crop yield of $2.38 \mathrm{tH}-1$ for southern regions. This shows that our system's fuzzy component worked properly. The success rate is high too as it has been matched with the practical experimental results, conducted on the trial farms.

Compared with the north, the lack of tube wells for irrigation in the south has in the past directly influenced the regional placement, extent, and crop alternatives. But our experimental results strongly show that crops such as wheat do exploit the natural cycle of shallow ground water through the process of capillary rise with grain yields of $2.4 \mathrm{tH}-1$ (dry land i.e. no irrigation) and $3.7 \mathrm{tH}-1$ (one irrigation) measured at trial sites on Bhola, one of the southern regions of Bangladesh.

According to our experimental findings, figure 13 presents a comparative analysis of potential crop yield in the northern Bangladesh with respect to the presence of water level on the ground and with a given certain amount of water irrigation. Figure 14 shows the same comparison for the southern Bangladesh. From figure 13 we can see that though northern Bangladesh is considered to be best suitable for Robi Crop production, without a good amount of irrigation we can't expect a good yield of crops. While in the southern Bangladesh, even without a single irrigation farmers can expect a certain amount of good crop yield due to the presence of shallow ground water after the wet season. Supplying water for irrigation is also very costly, so these results also will help the farmers to reduce their irrigation expenses according to the presence of shallow ground water. This finding is believed to be a ground breaking development in the agricultural sectors as it can solve the issues related to the shortage of farmlands and scarcity of water over the world.

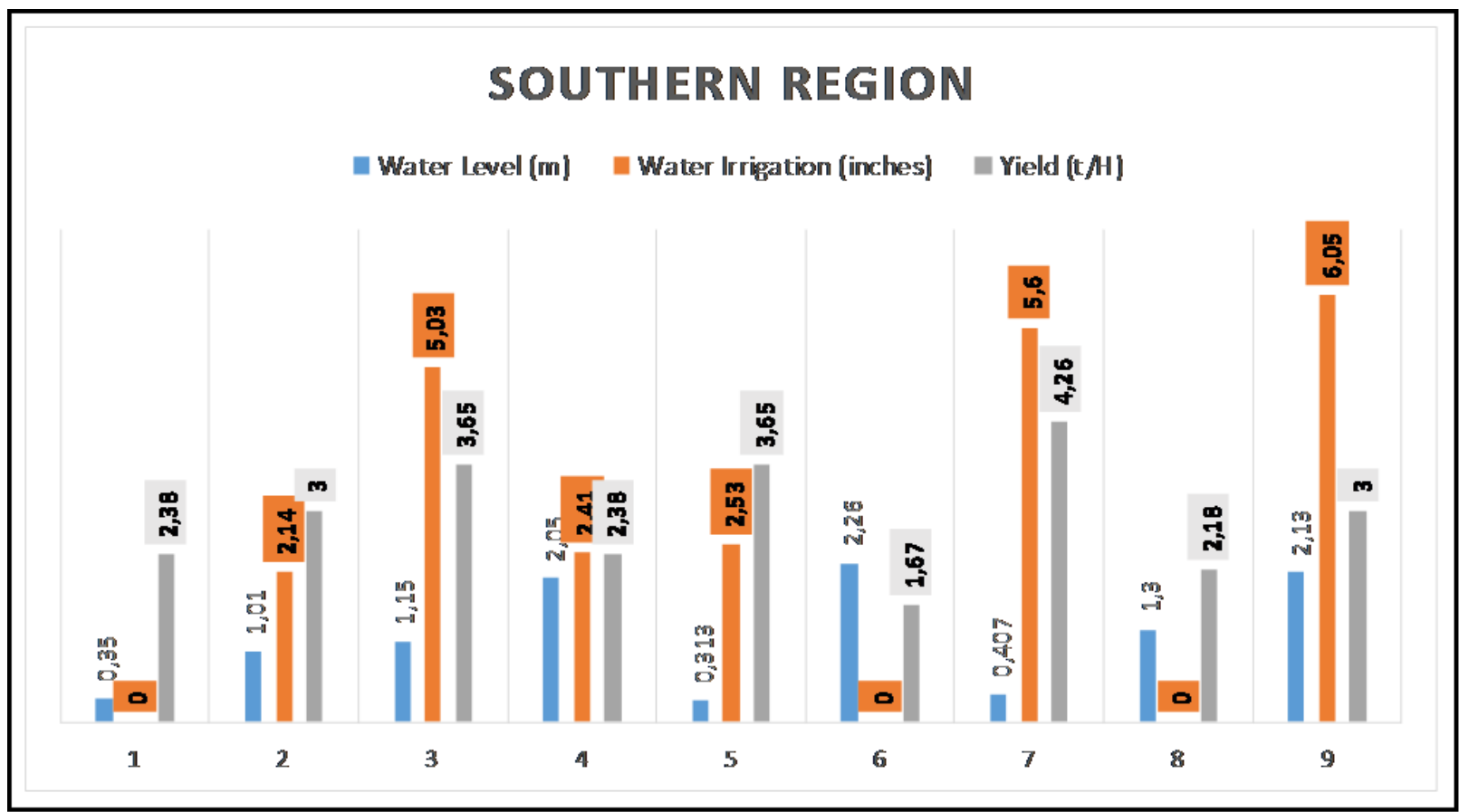

Fig 14: Potential Rate of crop yield in southern Bangladesh with a certain level of irrigation and water level present on the ground. 


\section{RESULT DISCUSSION AND CONCLUSION}

Agriculture has played, and continues to play a key role in the global economic development. Global food production is being undermined by land degradation and shortages of farmland and water resources. The past five decades have witnessed a significant rise in food production, but in many places, the better yields have been associated with agricultural practices that have degraded the land and water systems [30]. It's a demand of time now to explore new suitable areas for farming and crop productions.

In the past, coastal areas were considered as not suitable for the cultivation of Rabi Crops such as Wheat or Mung Bean because of their diverse nature of the soil. But the experimental results presented in this paper proves opposite to that.

The system presented in this paper shows the benefits of insitu crop water use resulting from the capillary rise, which has often been overlooked in providing soil water benefits in traditional irrigated farming systems. It demonstrates how to utilize this shallow ground water, an underutilized renewable resource for in-situ water used by Rabi crops such as Wheat or Mung bean in the southern part of Bangladesh. This shallow water is a resource that is routinely overlooked when water management alternatives are considered [31]. Compared with the north, the lack of tube-wells for irrigation in the south has in the past directly influenced the regional placement, extent and crop alternatives for southern farmers. This research has also challenged conventional thinking on potential areas for wheat cultivation in southern (the coastal area) Bangladesh with the introduction of new heat-tolerant varieties, improved agronomy, and technology.

The research discussed in this paper has shown that farmers in southern Bangladesh can produce significant wheat crops utilizing abundant surface water at the end of the wet season while benefiting from timely access to shallow groundwater from the process of capillary rise, compared to the northern regions where wheat is cultivated more but at the cost of declining water table levels because of relying too much on supplementary irrigation from deep tube wells. Our experimental results confirm crops such as wheat do indeed exploit the natural cycle of shallow ground water through the process of capillary rise with grain yields of $2.38 \mathrm{tH}-1$ (dryland i.e. no irrigation) and $3.65 \mathrm{tH}-1$ (one irrigation). Shallow ground water is a dynamic resource that can vary, both spatially between regions and in its timely availability to Rabi crops.

Taking agricultural decisions without consulting experts is one of the major problems that farmers in Bangladesh have to face. Generally taking a good decision at a proper time, directly affects the total production of the crop. Sometimes the process of taking a decision is complex, as there are several factors affecting entire farming process - especially the yield of crops. Farmers have to analyze these factors while taking decisions of farming and such decisions are changed area wise because geographical conditions differ from region to region.

The fuzzy logic based agricultural DSS developed in this paper also helps and assists farmers in this scenario on making good decisions for having a better crop production with minimized irrigational costs. The decision process, in this case, no doubt, is very complex and involves uncertainty. Hence Fuzzy logic is effectively and efficiently used to deal with this uncertainty. The presented system can be very easily used and it gives output as per the human agriculture expert. Taking into account the similar nature of the coastal regions of the world, this research work, if implemented properly is believed to be having a great impact in the terms of discovering new and potential farming areas which in turn will assist in the scenario of the shortage of farmlands and water resources.

\section{ACKNOWLEDGEMENTS}

Thanks to Dr. Mohammad Saifuzzaman, Dr. Perry L. Poulton and their research team of CIMMYT (International Maize and Wheat Improvement Center) for providing us their experimental tools and experiences while conducting our research, establishing our system module and verifying our experimental results.

\section{REFERENCES}

[1] "CIA - The World Factbook". Central Intelligence Agency. Archived from the original on 29 June 2011. Last Updated: Jun 05, 2014. https://www.cia.gov/library/publications/download

[2] Population Reference Bureau. 2015 World Population Data Sheet. Washington, D.C. Accessed at: http://www.prb.org/pdf15/2015-world population-datasheet_eng.pdf

[3] Johansson-Stenman, O., et al., Trust, trust games and stated trust: Evidence from rural Bangladesh. J. Econ. Behav. Organ. (2011), doi:10.1016/j.jebo.2011.06.022

[4] S.S. Hussain, H. Higgins, U.S. Embassy. USDA grain report: BG9003. Bangladesh Grain and Feed Annual 2009.

[5] Poulton, P.L., Saifuzzaman, M. 2010. Assessing potential additions to crop yields from shallow water tables for smallholder farmers during the Rabi season in southern Bangladesh. Proceedings of the 11th European Society of Agronomy Congress, August 28 - September 2010, Montpellier, France.

[6] Harvey, C.F., Ashfaque, K.N., Yu, W., Badruzzaman, A.B.M.,et al., 2006. Groundwater dynamics and arsenic contamination in Bangladesh, Chemical Geology, Volume 228, Issues 1-3, Controls on Arsenic Transport in NearSurface Aquatic Systems, 16 April 2006, Pages 112-136, ISSN 0009-2541

[7] Saifuzzaman, M., et al. "project Expanding the area for Rabi-season cropping in southern Bangladesh." (2012).

[8] K. Adhikari, B. Chakraborty, A. Gangopadhyay. Assessment of Irrigation Potential of Ground Water Using Water Quality Index Tool. Asian Journal of Water, Environment and Pollution. IOS Press. 2013

[9] Robins, N.S., Fergusson, J., 2014. Groundwater scarcity and conflict e managing hotspots. Earth Perspect. 1, 6.

[10] Landschoot, S., Waegeman, W., Audenaert, K., Van Damme, P., Vandepitte, J., De Baets, B., and Haesaert, G. 2013. A field-specific web tool for the prediction of Fusarium head blight and deoxynivalenol content in Belgium. Comput. Electron. Agric. 93:140-148.

[11] Sonal Dubey, R.K. Pandey, S.S. Gautam. Literature Review on Fuzzy Expert System in Agriculture. International Journal of Soft Computing and Engineering 
(IJSCE) ISSN: 2231-2307, Volume-2, Issue-6, January 2013

[12] Rajeshwar G Joshi, Parag Bhalchandra, Dr.S.D.Khmaitkar. Predicting Suitability of Crop by Developing Fuzzy Decision Support System. International Journal of Emerging Technology and Advanced Engineering. ISSN 2250-2459 (Online), An ISO 9001:2008 Certified Journal,Volume 3, Special Issue 2, January 2013

[13] Anna Perini and Angelo Susu, "Developing a Decision Support System for Integrated Production in Agriculture", Preprint submitted to Environmental Modelling and Software on 10 January 2003.

[14] DJ Power, R Sharda, F Burstein. Decision Support Systems Volume 7. Management Information Systems Published Online: 21 JAN 2015 DOI: 10.1002/9781118785317.weom070211

[15] Nam Nguyen, Malcolm Wegener, Iean Russell, "Decision support systems in Australian agriculture: state of the art and future development", Contributed paper prepared for presentation at the International Association of Agricultural Economists Conference, Gold Coast, Australia, August 12-18, 2006

[16] PP Mumba, E Kambwiri. Water Quality of Irrigation Water into and out of an Irrigated Sugar Cane Plantation. Asian Journal of Water, Environment and Pollution. IOS Press. 2013

[17] E Ostrom, WF Lam, M Lee. The Performance of SelfGoverning Irrigation Systems in Nepal. Human Systems Management, IOS Press, 1994

[18] Mirschel W, Wenkel K-O, Berg M, Wieland R, Nendel C, Köstner B, Topazh AG, Terleev VV, Badenko VL (2016) A spatial model-based decision support system for evaluating agricultural landscapes under the aspect of climate change. In: L. Mueller et al. (eds) Novel methods for monitoring and managing land and water resources in Siberia. Springer, Cham, pp 519-540 (Chapter 23 of this book)

[19] S. Madhan Babu, S. Pradeep, A. Shyamala, Ashutosh Das. Asian Journal of Water, Environment and pollution. IOS Press. 2007

[20] Stephen R. Heller, Stephen L. Rawlins. Agriculture systems research - A new initiative. Human Systems Management, 1986 - IOS Press. Pages: 289-296. June 14, 2013
[21] Parker, C.G. (1999), A user-centred design method for agricultural DSS. In U. Rickert (ed.) EFITA-99: Proceedings of the Second European Conference for Information Technology in Agriculture. Bonn, Germany. 27-30`h September 1999, Bonn: Universität Bonn-ILB. Vol A. pp. 395-404.

[22] Bryan Hosack, Dianne Hal, David Paradice, James F. Courtney. A Look Toward the Future: Decision Support Systems Research is Alive and Well. Journal of the Association for Information Systems Vol. 13, Issue 5, pp. 315-340, May 2012

[23] Edward C. Martin. Determining the Amount of Irrigation Water Applied to a Field. The University of Arizona College of Agriculture and life Sciences, Tucson, Arizona. 2006

[24] Verburg, K., 1996. Methodology in soil water and solute balance modelling: an evaluation of the APSIM-SoilWat and SWIMv2 models. CSIRO Division of Soils Technical Report No 131

[25] R. Bosma, J. Verreth, U. Kaymak, J. van den Berg, H. Udo. Using fuzzy logic modelling to simulate farmers' decision-making on diversification and integration in the Mekong Delta, Vietnam. Soft Comput (2011) 15:295310. DOI 10.1007/s00500-010-0618-7. Published online: 17 June 2010

[26] S. Madhan Babu, S. Pradeep, A. Shyamala, Ashutosh Das. Asian Journal of Water, Environment and pollution. IOS Press. 2007.

[27] Abu Sayed, Md. "Impact of lined canals on shallow tubewell irrigation and their acceptability by the farmers." (2010).

[28] Geebelen, Kristof, et al. "A MVC Framework for policybased adaptation of workflow processes: a case study on confidentiality." Web Services (ICWS), 2010 IEEE International Conference on. IEEE, 2010.

[29] Khanale P.B.,Ambilwade R.P.,2011,“A fuzzy Inference System for Diagnosis of Hyperthyrodism", Journal of Artificial Intelligence

[30] FAO. "The State of the World's Land and Water Resources for Food and Agriculture (SOLAW) Managing Systems at Risk." (2011): 288.

[31] Renard, D., et al. "Ecological engineers ahead of their time: The functioning of pre-Columbian raised-field agriculture and its potential contributions to sustainability today." Ecological Engineering 45 (2012): $30-44$. 